\title{
Dummies and the sudden infant death syndrome
}

\author{
E A Mitchell, B J Taylor, R P K Ford, A W Stewart, D M O Becroft, J M D Thompson, \\ R Scragg, I B Hassall, D M J Barry, E M Allen, A P Roberts
}

\begin{abstract}
The association between dummy use and sudden infant death syndrome (SIDS) was investigated in $\mathbf{4 8 5}$ deaths due to SIDS in the postneonatal age group and compared with 1800 control infants. Parental interviews were completed in $87 \%$ of subjects. The prevalence of dummy use in New Zealand is low and varies within New Zealand. Dummy use in the two week period before death was less in cases of SIDS than in the last two weeks for controls (odds ratio (OR) $0 \cdot 76,95 \%$ confidence interval (CI) 0.57 to 1.02). Use of a dummy in the last sleep for cases of SIDS or in the nominated sleep for controls was significantly less in cases than controls (OR $0.44,95 \%$ CI 0.26 to 0.73 ). The OR changed very little after controlling for a wide range of potential confounders.

It is concluded that dummy use may protect against SIDS, but this observation needs to be repeated before dummies can be recommended for this purpose. If dummy sucking is protective then it is one of several factors that may explain the higher mortality from SIDS in New Zealand than in other countries, and may also explain in part the regional variation within New Zealand.

(Arch Dis Child 1993; 68: 501-504)
\end{abstract}

Dummy (pacifier or comforter) use varies widely within and between countries. Much of the published work on dummies relates to their effect on dentition. ${ }^{1-4}$ Cozzi et al suggested that the use of a dummy might reduce the risk of sudden infant death syndrome (SIDS or cot death), ${ }^{5}$ but we are not aware of any study examining this hypothesis. This paper reports the relation between dummy use and the risk of SIDS in New Zealand.

Department of

Paediatrics, University of Auckland

J M D Thompson

Department of Community Health, University of Auckland

R Scragg

Office of the

Commissioner for

Children, Wellington

I B Hassall

Department of

Paediatrics, Hastings

D M J Barry

Department of

Paediatrics, Thames

E M Allen

Department of Paediatrics, Wellington A P Roberts

Correspondence to:

Dr Mitchell.

Accepted 18 November 1992 view (nominated date) was randomly selected from all 1096 days in the study period; (2) the control was then randomly allocated an age at which to be interviewed; (3) the date of birth was calculated from age and date of interview; (4) an obstetric hospital was randomly chosen in proportion to the number of births in 1986; and (5) random numbers were used to select a particular infant from those born on the date of birth in the nominated obstetric hospital.

Obstetric records were examined in 465 (96\%) of the cases and $1762(98 \%)$ of the controls. Parents (guardians) of subjects were interviewed and a wide range of topics was covered. Parental (guardian) interviews were completed in 393 $(81 \%)$ of cases and $1592(88 \%)$ of the controls. Eighty one per cent of the interviews with parents of cases were carried out within seven weeks of the infant's death, and $70 \%$ of the controls within four days of the nominated date. For questions on infant care practices that related particularly to the period before death in the cases, parents of controls were given a nominated time of day which was randomly allocated to match the estimated distribution of the time of death in cases.

The specific questions related to dummy use covered at the interview were: (1) in the last two weeks did baby use a dummy; and (2) if dummy used did baby use a dummy in the last sleep for cases and in the nominated sleep for controls?

Other variables examined related to the selection process (age of infant, region, season, and nominated time of day/time of death), sociodemographic (ethnic group, parental occupation, marital status, age mother left school, age of mother), pregnancy (age of mother at first pregnancy, number of previous pregnancies, months pregnant when first attended antenatal clinic, attended antenatal classes), and postnatal factors (infant's sex, birth weight, gestation, admission to special care baby unit, breast feeding only at discharge from obstetric hospital, maternal smoking in last two weeks, infant sleep position, and infant sharing a bed with another person). The definition of these variables have been described in detail previously. ${ }^{67}$ In addition, the respondent was asked if the infant was more than usually restless and irritable in the last two weeks and, if yes, was this in the last two days.

Relative risks were estimated by calculation of odds ratios (OR). The univariate ORs have confidence intervals (CIs) calculated by the method of Cornfield. The multivariate ORs are obtained from unconditional logistic regression modelling as are their CIs. The $\chi^{2}$ values are from $2 \times n$ contingency tables comparing dummy users with non-users.

Ethical approval for the study was obtained from each of the local ethics committees.

\section{Results}

Table 1 shows the percentages and ORs of the two questions relating to the use of dummies. In 
Table 1 Number (percentage), univariate, and multivariate odds ratios of variables related to the use of dummies (pacifiers)

\begin{tabular}{|c|c|c|c|c|}
\hline \multirow[b]{2}{*}{ Variable } & \multirow[b]{2}{*}{ Cases } & \multirow[b]{2}{*}{ Controls } & \multicolumn{2}{|c|}{ Odds ratio ( $95 \%$ confidence interval) } \\
\hline & & & Univariate & Multivariate ${ }^{\star}$ \\
\hline \multicolumn{5}{|c|}{ Dummy use in the two weeks before death/nominated time } \\
\hline Yes & $74(18.9)$ & $372(23 \cdot 4)$ & $0.76(0.57$ to 1.02$)$ & $0.71(0.50$ to 1.01$)$ \\
\hline No & $318(81 \cdot 1)$ & $1219(76 \cdot 6)$ & 1.00 & 1.00 \\
\hline \multicolumn{5}{|c|}{ Dummy use at death/nominated time } \\
\hline $\begin{array}{l}\text { Yes } \\
\text { No }\end{array}$ & $\begin{array}{r}19(4 \cdot 9) \\
372(95 \cdot 1)\end{array}$ & $\begin{array}{r}165(10 \cdot 4) \\
1421(89 \cdot 3)\end{array}$ & $\begin{array}{l}0.44(0.26 \text { to } 0.73) \\
1.00\end{array}$ & $\begin{array}{l}0.43(0.24 \text { to } 0.78) \\
1.00\end{array}$ \\
\hline
\end{tabular}

*Controlling for the following variables: infant's age, region, season, time of day, ethnic group, occupation, marital status of mother, age mother left school, age of mother, age of mother at first pregnancy, number of previous pregnancies, months pregnant when first attended antenatal clinic, attended antenatal classes, infant's sex, birth weight, gestation, admission to special care baby unit, breast feeding at discharge from obstetric hospital, maternal smoking in last two weeks, sleep position, and infant sharing bed with another person.

the two weeks before the death or nominated time for controls dummy use was less common in cases than in controls, but the difference was not significant at the $5 \%$ level (OR $0 \cdot 76,95 \%$ CI 0.57 to $1 \cdot 02)$. Dummy use in the last sleep for cases or in the nominated sleep for controls was significantly less in cases than in controls (OR $0.44,95 \%$ CI 0.26 to $0 \cdot 73$ ).

After controlling for region, season, marital status, ethnic group, occupation, age of mother at birth of infant, number of pregnancies, infant sex, birth weight, breast feeding, age of infant, sleep position, and infant sharing a bed with another person, use of dummy in the two week period before death/nominated time was significant at the $6 \%$ level (OR $0.71,95 \%$ CI 0.50 to 1.01 ) and use of dummy at the time of death/ nominated time was significantly associated with a decreased risk of SIDS (OR 0.43, 95\% CI 0.24 to $0 \cdot 78$ ).

As irritability or restlessness may promote the use of dummies we also controlled for this variable and found that again the OR changed very little.

To find out which infants were more likely to be dummy users we compared dummy users and non-users in the control group only (tables 2-4).
Table 2 shows the sociodemographic variables. Infants of younger mothers and younger school leaving age were more likely to use dummies. Table 3 shows the variables related to pregnancy. Infants of mothers who attended antenatal clinics early were more likely to use a dummy. Table 4 shows the variables related to postnatal factors. Infants who were breast fed or slept prone were less likely to use a dummy.

\section{Discussion}

Dummy use varies considerably between countries. In Milwaukee, dummy use at three months is high at $88 \%,{ }^{8}$ although prevalence figures between 35 and $45 \%$ have more often been reported..$^{23}$ One previous report from New Zealand found that the prevalence of dummy use in the first 12 months of life was $9 \% .{ }^{9}$ As dummy sucking is initiated by the infants' parents such wide variation in the prevalence of dummy use would be expected to reflect the cultural and dental attitudes of the community rather than differences in infants. Interestingly, in New Zealand, dummy use has been strongly discouraged in the past and this probably accounts for its now relatively rare use. ${ }^{10}$

Published work on dummy use predominantly relates to its effects on dental malocclusion, ${ }^{1-3}$ and suggests that any effects are small and disappear with time when the habit stops. As malocclusion may be worse with finger sucking, it has been suggested that parents should encourage dummy sucking in children who show signs of being potential finger suckers to prevent this habit from arising. ${ }^{11}$ The other area of concern with dummies for the dental profession relates to dental caries, which seems to be a problem only if the dummy is sweetened. ${ }^{+}$

Information on infant deaths and dummies is sparse. Dummies as the cause of occasional asphyxial deaths from impaction in the airway have been reported in older children.'2 Some deaths have also occurred by strangulation by

Table 2 The use of dummies by variables related to sociodemographic factors for the control infants

\begin{tabular}{|c|c|c|c|c|c|c|}
\hline & \multicolumn{3}{|c|}{ Dummy use in two weeks before nominated time } & \multicolumn{3}{|c|}{ Dummy use at nominated time } \\
\hline & Yes $(\%)$ & $\mathrm{No}(\%)$ & $\chi^{2}(p$ value $)$ & Yes $(\%)$ & $\mathrm{No}(\%)$ & $\chi^{2}(p$ value $)$ \\
\hline \multicolumn{7}{|l|}{ Socioeconomic status } \\
\hline I, II & $120(22 \cdot 1)$ & $423(77 \cdot 9)$ & & $50(9 \cdot 3)$ & $490(90 \cdot 7)$ & \\
\hline III, IV & $193(25 \cdot 6)$ & $560(74 \cdot 4)$ & $4 \cdot 24(0 \cdot 109)$ & $93(12 \cdot 4)$ & $657(87 \cdot 6)$ & $6.65(0.036)$ \\
\hline $\mathrm{V}, \mathrm{VI}$, and others & $59(20 \cdot 1)$ & $235(79 \cdot 9)$ & & $22(7 \cdot 5)$ & $272(92 \cdot 5)$ & \\
\hline \multicolumn{7}{|l|}{ Region } \\
\hline Äuckland & $172(32 \cdot 3)$ & $361(67 \cdot 7)$ & & $78(14 \cdot 7)$ & $452(85 \cdot 3)$ & \\
\hline Central North Island & $116(24 \cdot 3)$ & $362(75 \cdot 7)$ & & $56(11 \cdot 8)$ & $420(88 \cdot 2)$ & \\
\hline $\begin{array}{l}\text { Couthern North isiand } \\
\text { Christchurch }\end{array}$ & $\begin{array}{l}49(20 \cdot 3) \\
29(16 \cdot 6)\end{array}$ & $\begin{array}{l}190(79 \cdot 5) \\
146(83 \cdot 4)\end{array}$ & $66.42(0 \cdot 000)$ & $\begin{array}{l}16(6 \cdot \%) \\
14(8 \cdot 0)\end{array}$ & $\begin{array}{l}222(93 \cdot 3) \\
161(92 \cdot 0)\end{array}$ & $41 \cdot 53(0 \cdot 000)$ \\
\hline Southern South Island & $6(3 \cdot 6)$ & $160(96 \cdot 4)$ & & $1(0 \cdot 6)$ & $165(99 \cdot 4)$ & \\
\hline \multicolumn{7}{|l|}{ Ethnic group } \\
\hline Maori & $60(20 \cdot 0)$ & $240(80 \cdot 0)$ & & $23(7 \cdot 7)$ & $276(92 \cdot 3)$ & \\
\hline Pacific Islander & $28(20 \cdot 4)$ & $109(79 \cdot 6)$ & $3 \cdot 55(0 \cdot 170)$ & $7(5 \cdot 1)$ & $130(94 \cdot 9)$ & $8 \cdot 70(0 \cdot 013)$ \\
\hline \multirow{2}{*}{\multicolumn{7}{|c|}{ Age mother left school (years) }} \\
\hline & & & & & & \\
\hline 16 & $126(24 \cdot 9)$ & $379(75 \cdot 1)$ & $9.09(0.011)$ & $64(12 \cdot 7)$ & $439(87 \cdot 3)$ & $10 \cdot 66(0.005)$ \\
\hline \multicolumn{7}{|l|}{ Married } \\
\hline Yes & $266(22 \cdot 6)$ & $913(77 \cdot 4)$ & $1.70(0.191)$ & $116(9.9)$ & $1059(90 \cdot 1)$ & $1.41(0.235)$ \\
\hline & & $49(12 \cdot 0)$ & $361(88 \cdot 0)$ & $1.41(0.253)$ \\
\hline$<20$ & $34(28 \cdot 6)$ & $85(71 \cdot 4)$ & & $13(11 \cdot 0)$ & $105(89 \cdot 0)$ & \\
\hline $20-24$ & $97(27 \cdot 2)$ & $259(72 \cdot 8)$ & $7.58(0.055)$ & $46(13.0)$ & $309(87 \cdot 0)$ & $9.07(0.028)$ \\
\hline $\begin{array}{l}25-29 \\
30+\end{array}$ & $124(22 \cdot 0)$ & $439(78 \cdot 0)$ & (2030) & $64(11 \cdot 4)$ & $497(88 \cdot 6)$ & $907(0.020)$ \\
\hline $30+$ & $112(20 \cdot 7)$ & $430(19 \cdot 3)$ & & $39(7 \cdot 2)$ & $501(92 \cdot 8)$ & \\
\hline
\end{tabular}


Table 3 The use of dummies by variables related io pregnancy for the control infants

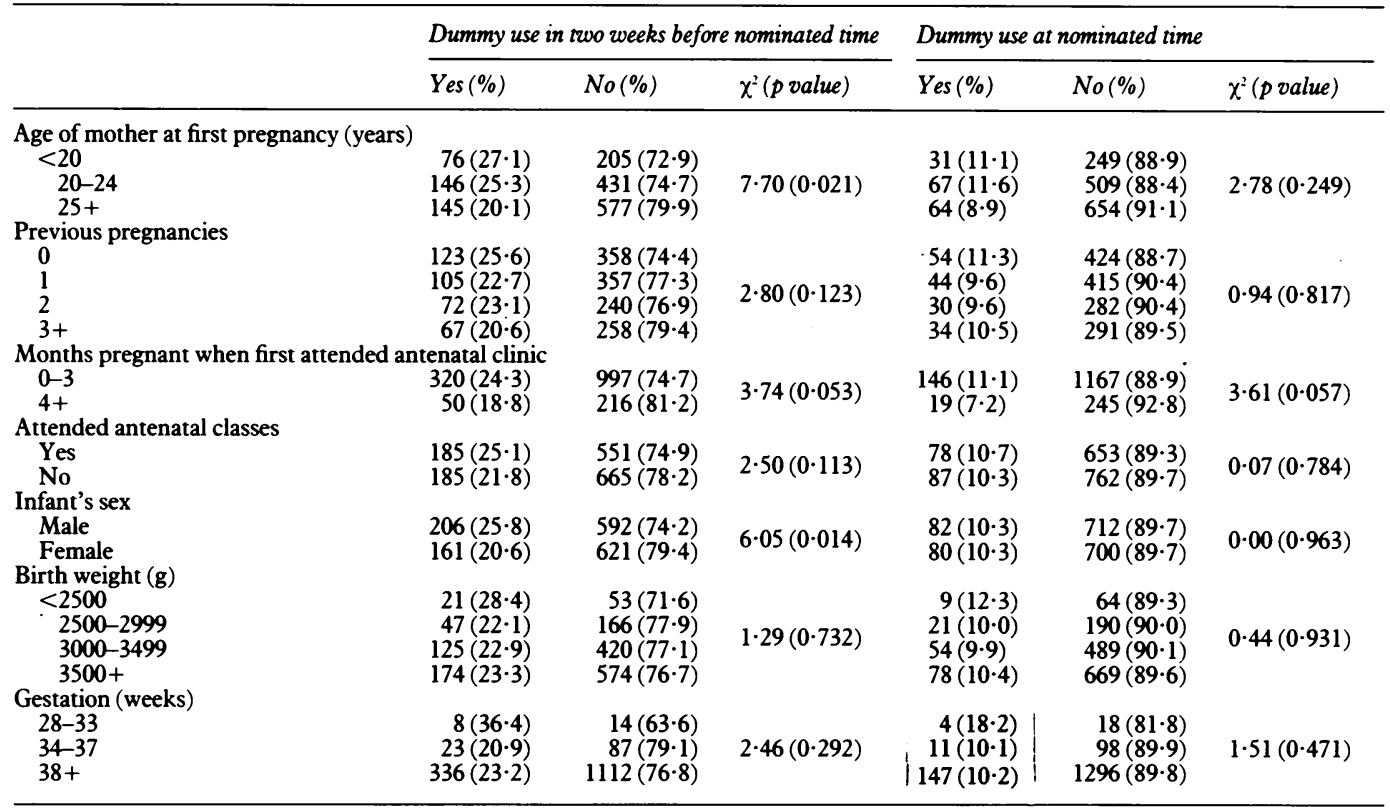

cords, which may be used to tie the dummy around the neck of the infant. ${ }^{13}$

Cozzi et al suggested that in SIDS a vacuum might occur in the pharynx, pulling the tongue back and blocking the airway. ${ }^{5}$ They suggested that a dummy might prevent the tongue sealing off the airway. To our knowledge, however, this hypothesis has not been tested.

In this study dummy use in cases in the two weeks before death was less common than for controls, but did not reach significance at the $5 \%$ level. Dummy use in the sleep at the time of death, or at the nominated sleep for controls, however, was significantly less for the cases than for the controls. Moreover, after controlling for a wide range of possible confounders, including maternal age, education, breast feeding, infant's sleeping position, and irritability, dummy use continued to be protective.

This study confirms the low rate of use of dummies in New Zealand. ' Not only is dummy use rare in New Zealand, but dummy use is also intermittent. A total of $23 \%$ of control infants used a dummy in the previous two weeks, but only $10 \%$ of infants used a dummy during the nominated sleep. If dummy use is protective then it is one of several factors that might explain the higher rate of mortality from SIDS in New Zealand.

We found marked regional variations in the use of dummies, with less than $5 \%$ of controls in southern New Zealand using dummies compared with $32 \%$ using dummies in the Auckland region (northern New Zealand). This difference may reflect the strength of advice on child care practices in each area. This is one of several factors which may explain the north-south variation in SIDS mortality in New Zealand. Dummy use was more common in infants with young mothers and mothers who left school at an early

Table 4 The use of dummies by variables related to postnatal factors for the control infants

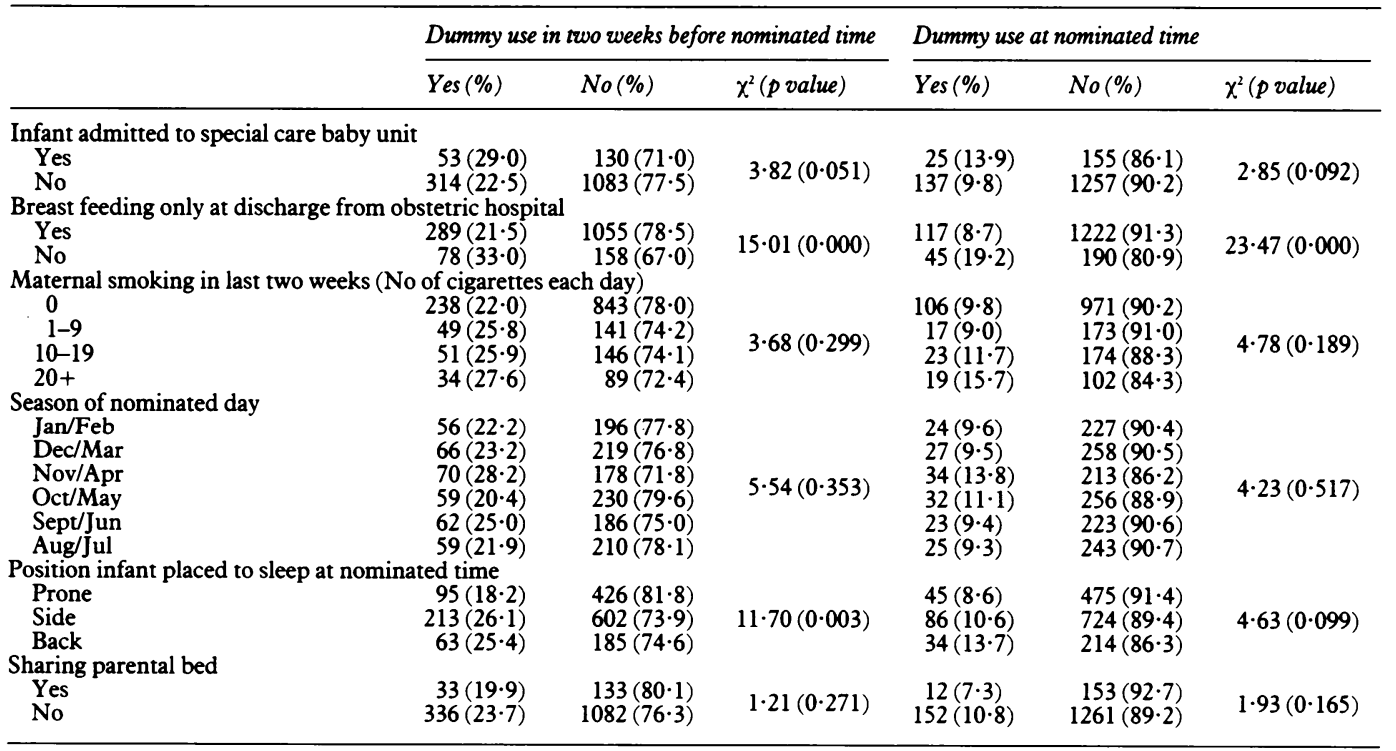


age. Dummy use was also more common in infants of mothers who attended antenatal clinics early.

Breast fed infants were less likely to use a dummy than bottle fed infants. There are several plausible explanations for this: $(a)$ it seems likely that an unsettled breast fed infant would be offered the breast rather than the dummy as a method of comforting; or $(b)$ offering a dummy may be counter productive in successfully establishing breast feeding. When breast feeding was taken into account in the logistic regression, however, the apparent beneficial effect of dummy usage in lessening SIDS risk remained unchanged.

Infants placed to sleep prone were less likely to use a dummy than infants placed in the nonprone position. The reason for this may be purely mechanical in that sucking on a dummy with the face down is impracticable. Also there is evidence that prone sleeping is associated with more rapid settling of the infant ${ }^{14}$ is and hence may circumvent the need to resort to a dummy.

The nature of the infant must also be taken into account. The act of offering a dummy to a child will be to some extent determined by the temperament of the infant. The more passive and quiet infant (perhaps even neurologically damaged) is not such a disturbance to the parents and therefore is unlikely to be given a dummy, whereas the more active and demanding infant may be strongly encouraged to suck on a dummy. When an indicator of irritability or restlessness was introduced into the model, however, again no decrease in the dummy's apparent protective effect was seen.

The sucking of fingers instead of (or in addition to) a dummy should also be taken into account. Unfortunately, we do not have any information on this, though data are currently being collected in another project.

How might dummy use be protective? The mechanism proposed by Cozzi et al may be one method..$^{5}$ Alternatively, dummy use may result in a reduction in gastro-oesophageal reflux, ${ }^{16}$ which has been related to apnoeas, though the relation between gastro-oesophageal reflux and apnoeas is controversial. ${ }^{17}$ Perhaps of more importance is upper airway muscle tone, which is dependent on sensory input. Active protrusion of the tongue, which occurs with normal dummy sucking, will keep the tongue forward and thus help to maintain upper airway patency.
Dummy use is relatively uncommon in New Zealand and if it was to be confirmed to have a protective effect its promotion could reduce the number of deaths from SIDS by about $50 \%$. We do advise caution and we emphasise that we have not advised the promotion of dummy use in the National Cot Death Prevention Campaign currently being run in New Zealand. ${ }^{18}$ This new association of dummy use and a lower risk of SIDS is provisional and this observation urgently needs to be repeated in another community and the possible mechanisms examined. Whether thumb or finger sucking is equally protective is not known as information on this variable was not collected in this study, but future studies should explore this.

This study was funded by the Health Research Council of New Zealand and the Hawkes Bay Medical Research Foundation. Mrs C Everard coordinated the study. Mrs C Everard, Mr A Stewart and $\mathrm{Mr} \mathrm{J}$ Thompson were supported by the HRCNZ. We thank Dr Murray Laugesen who drew our attention to Cozzi's hypothesis.

1 Larsson E. The effect of dummy-sucking on the occlusion: a review. Eur f Orthod 1986; 8: 127-30.

2 Winter GB. Problems involved with the use of comforters. Int Dent f 1980; 30: 28-38.

3 Larsson EF, Dahlin KG. The prevalence and the etiology of the initial dummy- and finger-sucking habit. Am $\mathcal{F}$ Orthod 1985; 87: 432-5.

4 Winter GB, Hamilton MC, James PM. Role of the comforter as an aetiological factor in rampant caries of the decidious dentition. Arch Dis Child 1966; 41: 207-12.

5 Cozzi F, Albani R, Cardi E. A common pathophysiology for sudden cot death and sleep apnoea. "The vacuumglossoptosis syndrome'. Med Hypotheses 1979; 5: 329-38.

6 Mitchell EA, Scragg R, Stewart AW, et al. Results from the first year of the New Zealand cot death study. $N \mathrm{Z} \mathrm{Med} \mathcal{F}$ 1991; 104: 71-6.

7 Mitchell EA, Taylor BJ, Ford RPK, et al. Four modifiable and other major risk factors for cot death: the New Zealand other major risk factors for cot death: the New Zeal

8 Passmann RH, Halonen JS. A developmental survey of young childrens' attachment to inanimate objects. $\mathcal{F}$ Genet Psychol 1979 ; 134: 165-78.

9 Wooding AR, Boyd J, Geddis DC. Sleep patterns of New Zealand infants during the first 12 months of life. $\mathcal{F}$ Paediatr Child Health 1990; 26: 85-8.

10 King FT. Dummy or comforter. In: King FT, ed. Feeding and care of baby. London: MacMillan, 1931: 132-5.

11 Cerny R. Thumb and finger sucking. Aust Dent $f$ 1981; 26: $167-71$.

12 Brandt-Casadevall C, Gujer HR, Bozic C, Dangel P. Exceptional death by deep introduction of a dummy into the tional death by deep introduction of a

13 Feldman KW, Simms RJ. Strangulation in childhood: epidemiology and clinical course. Pediatrics 1980; 65: 1079-85.

14 Keitel HG, Cohn R, Harnish D. Diaper rash, self-inflicted excoriations and crying in full-term newborn infants kept in the prone or supine position. $\mathcal{F}$ Pediatr 1960; 57: 884-6.

15 Brackbill Y, Douthill TC, West H. Psychophysiologic effects in the neonate of prone versus supine placement. $\mathcal{F}$ Pediatr 1973; 82: 82-4.

16 Orenstein SR. Effect of non-nutritive sucking on infant gastroesophageal reflux. Pediatr Res 1988; 24: 38-40.

17 Anonymous. Gastro-oesophageal reflux and apparent lifethreatening events in infancy [Editorial]. Lancet 1988; ii: 261-2.

18 Mitchell EA, Aley P, Eastwood J. The national cot death prevention programme in New Zealand. Australian foumal of Public Health 1992; 16: 158-61 